\title{
Specific in vitro interferon-gamma and IL-2 production as biomarkers during treatment of chronic $\mathrm{O}$ fever
}

\section{Teske Schoffelen ${ }^{1}$, Marjolijn C. Wegdam-Blans ${ }^{2}$, Anne Ammerdorffer ${ }^{1}$, Marjolijn J. H. Pronk ${ }^{3}$, Yvonne E. P. Soethoudt ${ }^{4}$, Mihai G. Netea ${ }^{1}$, Jos W. M. van der Meer ${ }^{1}$, Chantal P. Bleeker-Rovers ${ }^{1}$ and Marcel van Deuren ${ }^{1}$}

\author{
Department of Internal Medicine, Radboud University Medical Center, Nijmegen, Netherlands \\ 2 Department of Medical Microbiology, Laboratory for Pathology and Medical Microbiology, Veldhoven, Netherlands \\ ${ }^{3}$ Department of Internal Medicine, Catharina Hospital, Eindhoven, Netherlands \\ ${ }^{4}$ Department of Internal Medicine, Elkerliek Hospital, Helmond, Netherlands
}

\section{Edited by:}

Evangelos Giamarellos-Bourboulis, University of Athens, Greece

\section{Reviewed by:}

Malgorzata Anna

Mikaszewska-Sokolewicz, The Medical University of Warsaw, Poland Efthymia Giannitsioti, Attikon University General Hospital, Greece

\section{*Correspondence:}

Teske Schoffelen, Department of Internal Medicine, Radboud University Medical Center, Geert Grooteplein-Zuid 10, 6525 GA Nijmegen, Netherlands e-mail:Teske.Schoffelen@ radboudumc.nl

Background: Antibiotic treatment of chronic $\mathrm{Q}$ fever is cumbersome and of long duration. To monitor treatment, there is a need for alternative biomarkers. Coxiella burnetii-specific interferon (IFN)- $\gamma$ and interleukin (IL)-2 production reflect the type of effector and memory T-cell response. In chronic $\mathrm{Q}$ fever, $\mathrm{C}$. burnetii-specific IFN- $\gamma$ production is higher and IL2 production is lower than in individuals with past $\mathrm{Q}$ fever. Here we explore whether $C$. burnetii-specific IFN- $\gamma$ and IL-2 production correlate to treatment response.

Methods: We studied the longitudinal $C$. burnetii-specific IFN- $\gamma /$ IL-2 ratio in fifteen proven chronic $\mathrm{Q}$ fever patients. All patients were followed for at least 18 months during antibiotic treatment. Treatment was considered successful when clinical recovery was observed, a positive PCR for $C$. burnetii DNA in blood became persistently negative, anti-phase I lgG showed a fourfold decrease or more, and imaging techniques showed disappearance of infectious foci.

Results: Overall, the IFN- $\gamma / \mathrm{LL}-2$ ratio declined when patients experienced a successful treatment outcome. When treatment failed, IFN- $\gamma / \mathrm{IL}-2$ ratios did not significantly decrease. The median $( \pm I \mathrm{IQR})$ slope of the longitudinal IFN- $\gamma / \mathrm{LL}-2$ ratio with successful treatment was $-2.10(-7.02$ to -0.06$)$, and $-0.15(-1.13$ to 0.25$)$ with unsuccessful treatment $(P=0.19)$. $\mathrm{Q}$ fever endocarditis patients had higher IFN- $\gamma / \mathrm{LL}-2$ ratios than patients with endovascular infections.

Conclusion: We propose that the IFN- $\gamma / \mathrm{LL}-2$ ratio can be used as an additional biomarker for monitoring chronic $\mathrm{Q}$ fever treatment, with declining ratios being indicative of successful treatment.

Keywords: Q fever, Coxiella burnetii, cell-mediated immunity, interferon-gamma, interleukin-2, biomarker, serology, treatment

\section{INTRODUCTION}

$\mathrm{Q}$ fever is a zoonosis, caused by the Gram-negative, intracellular bacterium Coxiella burnetii (Raoult et al., 2005; Parker et al., 2006). Following primary infection, $1-5 \%$ of patients develop chronic infection, which can become clinically overt months to years later (Maurin and Raoult, 1999). Endocarditis and infection of a vascular aneurysm or prosthesis are the most common manifestations of chronic Q fever (Botelho-Nevers et al., 2007; Million et al., 2010). Pre-existent cardiac valvular abnormalities, aortic aneurysms, vascular grafts, and immune-compromised state are risk factors (Raoult et al., 2000; Fenollar et al., 2001; Landais et al., 2007).

Clinical symptoms of chronic Q fever are often non-specific, and the diagnosis relies on identifying pre-existing risk-factors, the results of anti-C. burnetii serology and PCR for C. burnetii DNA on blood or tissue, and results of imaging techniques (Wegdam-Blans et al., 2012a; Anderson et al., 2013). Untreated chronic infection leads to severe morbidity, with a mortality up to $60 \%$ (Million et al., 2010). Long-term antibiotics, preferably doxycycline combined with hydroxychloroquine (Raoult et al., 1999; Kersh, 2013), are required to eliminate $C$. burnetii. Antibiotics should be administered for at least 18 months or, in case of a valvular/vascular prosthesis, for at least 24 months (Million et al., 2010). Surgical intervention to replace an infected vascular aneurysm/graft or cardiac valve is often necessary, either in the acute situation of a symptomatic aortic aneurysm or heart failure, or when a patient does not improve on antibiotics (Botelho-Nevers et al., 2007; Kampschreur et al., 2012; Wegdam-Blans et al., 2012b).

The discontinuation of antimicrobial therapy strongly depends on the results of follow-up imaging. In case of vascular infection focus, ${ }^{18} \mathrm{~F}$-fluorodeoxyglucose Positron Emission Tomography/Computed Tomography (FDG-PET/CT) is preferred, which has high sensitivity and specificity for low-grade vascular infections (Merhej et al., 2012; Barten et al., 2013). In cases of Q fever endocarditis, vegetations are difficult to detect on echocardiography, and a negative echocardiogram does not rule out endocarditis 
(Maurin and Raoult, 1999). Therefore, serology is an important tool during the antibiotic treatment of chronic Q fever. Chronic infection is characterized by high titres of anti-phase I IgG antibodies. It is assumed that antibiotic treatment should be continued until these titres have declined at least fourfold, or until titres are below 1:800 in immunofluorescence assay [IFA, or below 1:1024 in a commercial available IFA (Focus Diagnostics) ]; (Million et al., 2010). In daily practice, the slow serological decline requires longer treatment, and titres often remain above 1:800 (or above 1:1024 respectively) for a prolonged time.

These limitations show the need for additional biomarkers to monitor treatment of chronic Q fever. In this respect, laboratory tests measuring cell-mediated immune responses may be of value. Interferon-gamma (IFN- $\gamma$ ) plays a pivotal role in the immune response against the intracellular $C$. burnetii (Dellacasagrande et al., 1999; Andoh et al., 2007). Analogous to IFN- $\gamma$ release assays (IGRAs) that are widely used in Mycobacterium tuberculosis infection (Pai et al., 2004), we previously used whole-blood assays to show that the $C$. burnetii-specific IFN- $\gamma$ production is significantly increased in people that have been exposed to $C$. burnetii (Schoffelen et al., 2013). The interpretation of IFN- $\gamma$ production in chronic $\mathrm{Q}$ fever is complex, since IFN- $\gamma$ production is a marker of both immunity and infection. We demonstrated, by measuring a broad panel of cytokines, that ex-vivo C. burnetii-specific IFN- $\gamma$ production is higher and interleukin (IL)-2 production is lower in chronic Q fever patients than in patients with past $\mathrm{Q}$ fever (Schoffelen et al., 2014), and concluded that a high IFN$\gamma /$ IL-2 ratio has a high specificity to discriminate between these two groups.

The present study follows the hypothesis that the IFN- $\gamma /$ IL-2 ratio will decline during effective treatment of chronic $\mathrm{Q}$ fever. To test this, we followed 15 chronic $Q$ fever patients for at least 18 months during antibiotic treatment and performed wholeblood stimulation assays with measurement of IFN- $\gamma$ and IL- 2 on a regularly basis. This study is the first evaluation of a cell-mediated immunity biomarker for treatment of chronic Q fever.

\section{MATERIALS AND METHODS PATIENTS AND FOLLOW-UP}

Fifteen chronic Q fever patients, recruited from participating hospitals, were followed in this study for at least 18 months. The study was approved by the Medical Ethical Committee ArnhemNijmegen and written informed consent was obtained from all subjects. At the time of diagnosis, all patients had a positive PCR in blood, serum and/or tissue, and anti-phase I IgG titres $\geq 1: 1024$ (in the absence of acute $\mathrm{Q}$ fever). Four patients were diagnosed with endocarditis according to the modified Duke criteria $(n=4)$, and eleven had vascular infection. All fulfilled the criteria of 'proven chronic Q fever' of the Dutch consensus group on chronic Q fever (Wegdam-Blans etal., 2012a). Patients were included at different time points after start of treatment. The start of antibiotic treatment was designated $t=0$. The three patients that were included at the start of treatment or within 2 months after start of treatment are described in more detail. Treatment was considered successful when clinical recovery was observed, a positive PCR for C. burnetii DNA on blood became persistently negative, antiphase I IgG showed a fourfold decrease or more (related to the maximum titre), and imaging techniques showed disappearance of any (vascular or valvular) infectious foci.

\section{WHOLE BLOOD INCUBATION}

Venous blood drawn into $5 \mathrm{~mL}$ endotoxin-free lithium-heparin tubes (Vacutainer, BD Biosciences) was processed within $12 \mathrm{~h}$. Blood was aliquoted in separate tubes and incubated at $37^{\circ} \mathrm{C}$ for 24 h with heat-inactivated C. burnetii Nine Mile (NM) RSA493 phase I (Seshadri etal., 2003), mitogen (positive control) or without (negative control).

C. burnetii $\mathrm{NM}$ was used in an end-concentration of $10^{7}$ bacteria/mL. Bacteria were cultured in a BSL-3 facility at the Central Veterinary Institute (Lelystad, the Netherlands) as previously described (Schoffelen et al., 2013) and kindly provided by Dr. H. J. Roest. The same batch was used for all assays. The mitogen phytohemagglutinin (PHA, Sigma-Aldrich, St. Louis, MO, USA; $10 \mu \mathrm{g} / \mathrm{mL}$ ) was used as a positive control. After incubation, blood cultures were centrifuged at $4656 \mathrm{~g}$ for $10 \mathrm{~min}$ and supernatants were stored at $-20^{\circ} \mathrm{C}$ until assayed.

\section{CYTOKINE MEASUREMENTS}

Interferon- $\gamma$ concentration in supernatants was measured using a commercial enzyme-linked immunosorbent assay (ELISA; Pelikine compact, Sanquin, Amsterdam, the Netherlands) as previously described (Schoffelen et al., 2014). The background IFN- $\gamma$ response of the negative control aliquot was subtracted from the stimulated aliquots for each individual sample. In all negative control aliquots, the highest IFN- $\gamma$ concentration was $46 \mathrm{pg} / \mathrm{mL}$, which was considered acceptable. In addition, all samples showed a net IFN $-\gamma$ production $>24 \mathrm{pg} / \mathrm{mL}$ in either the positive control aliquot or in the C. burnetii-stimulated aliquot. Thus, all samples were considered valid. IL-2 concentrations in supernatant of the $C$. burnetii-stimulated aliquots were measured using luminex magnetic beads assay (Merck Millipore, Billerica, MA, USA) according to the manufacturer's instructions.

\section{ANALYSIS}

Graphpad Prism (Graphpad software Inc., version 5) was used to make the graphs and to analyze the data. Non-linear regression to a straight line with least square fit was performed to obtain the best-fit slope of the IFN- $\gamma / \mathrm{IL}-2$ ratio of each patient over time. Median \pm interquartile range (IQR) slope was compared between groups.

\section{RESULTS \\ CASE 1: A PATIENT WITH C. burnetii-INFECTED VASCULAR PROSTHESIS WITH SUCCESSFUL TREATMENT}

A 30-years-old man with a medical history of traumatic rupture of the thoracic aorta, for which he had undergone vascular surgery receiving an endoprosthesis, suffered from new symptoms of malaise, night sweats, weight loss, and chills. Because of the preceding Q fever epidemic, serology for C. burnetii was performed, revealing chronic infection with very high IgG titers against phase I and II (both 1:65536). PCR on serum for C. burnetii DNA was positive. He was not aware of a preceding acute Q fever episode. FDG-PET/CT showed no signs of infection at the thoracic aortic prosthesis, nor elsewhere. Transesophageal echocardiogram 
A

¿ anti-phase I lgG

$\diamond$ IFN- $\gamma$

$\downarrow$ IFN- $\gamma /$ IL-2 ratio

$\diamond$ IL-2
PATIENT 1

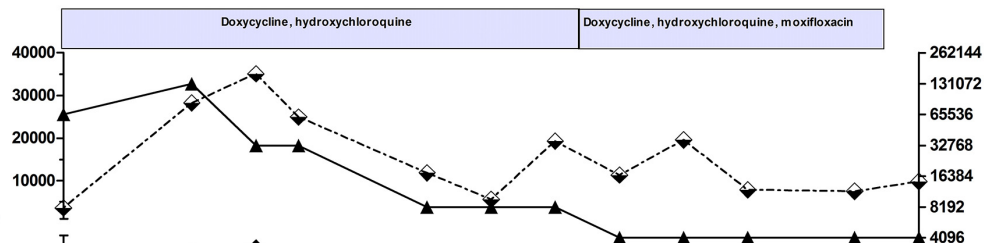

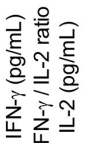

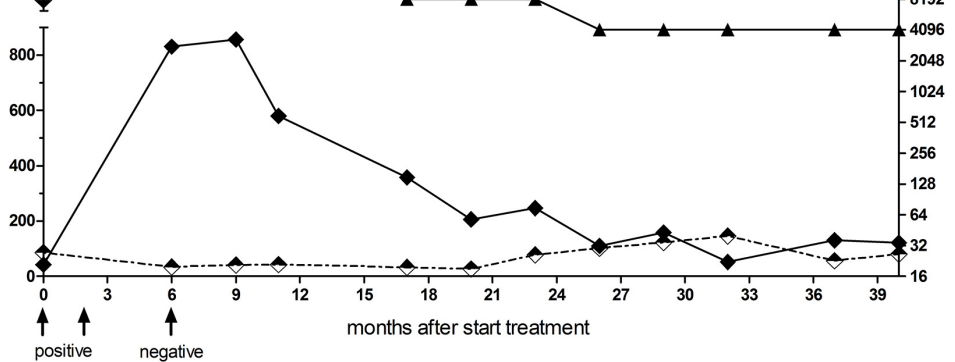

PCR blood

B

PATIENT 2

$\downarrow$ anti-phase $1 \mathrm{lgC}$

$\diamond$ IFN- $\gamma$

$\rightarrow$ IFN- $\gamma /$ IL-2 ratio

$\rightarrow$ IL-2
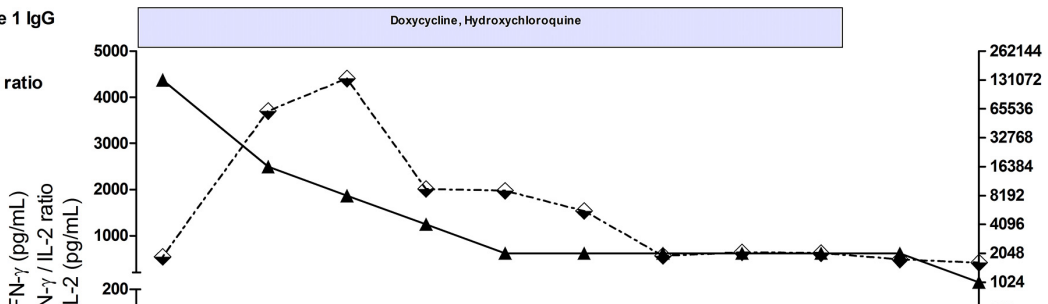

200
$150-$

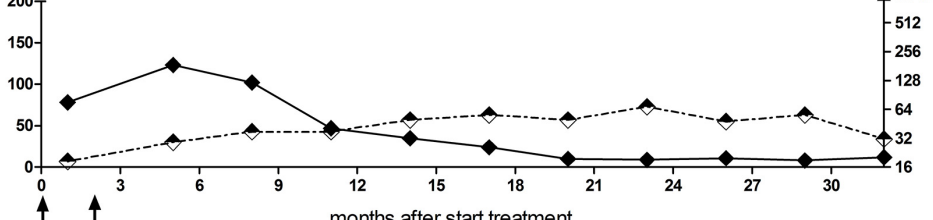

C

PATIENT 3

^ anti-phase I lgG

$\diamond$ IFN- $\gamma$

- IFN- $\gamma / \mathrm{IL}-2$ ratio

$\rightarrow$ IL-2

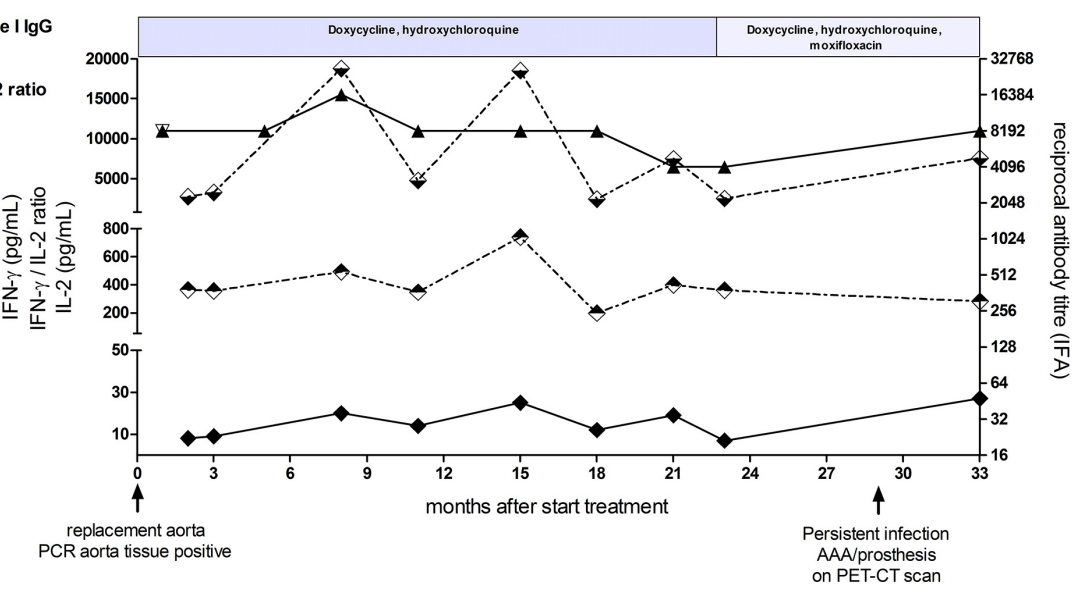

FIGURE 1 | Detailed overview of immunological parameters in (A) patient 1 (B) patient 2, and (C) patient 3 from start of antibiotic treatment to end of study follow-up. The IFN- $\gamma$ and IL-2 concentrations (dotted lines) and the IFN- $\gamma / \mathrm{IL}-2$ ratio (black diamant) are shown on the left $y$-axis, the anti-phase I lgG antibody-titer (black triangle) is shown on the right $y$-axis. The course of antibiotic treatment is depicted above each graph. 
Table 1 | Clinical features of the chronic $\mathbf{Q}$ fever patients.

\begin{tabular}{|c|c|c|c|c|c|c|c|c|}
\hline $\mathrm{Nr}$ & Sex & $\begin{array}{l}\text { Age } \\
\text { (yrs) }^{a}\end{array}$ & Focus of infection & $\begin{array}{l}\text { IgG anti-phase } \\
\text { I titre }{ }^{a, b}\end{array}$ & $\begin{array}{l}\text { IgG anti-phase } \\
\text { II titre } \\
\text { a,b }\end{array}$ & $\begin{array}{l}\text { PCR serum/ } \\
\text { plasma }^{a}\end{array}$ & PCR tissue & $\begin{array}{l}\text { Duration of antibiotic } \\
\text { treatment (months) }\end{array}$ \\
\hline 2 & Male & 66 & Aortic valve & 131072 & 131072 & Pos & Pos & 1 \\
\hline 3 & Male & 64 & Aortic aneurysm & 8192 & 8192 & Neg & Pos & 2 \\
\hline 4 & Male & 46 & Vascular graft & 65536 & 131072 & Pos & n.a. & 7 \\
\hline 6 & Male & 72 & Vascular graft & 16384 & 8192 & Neg & Pos & 9 \\
\hline 7 & Male & 74 & Aortic aneurysm & 65536 & 32768 & Neg & Pos & 4 \\
\hline 8 & Female & 54 & Vascular graft & 4096 & 4096 & Neg & Pos & 24 \\
\hline 9 & Male & 79 & Prosthetic aortic valve & 4096 & 4096 & Pos & n.a. & 20 \\
\hline 13 & Male & 71 & Vascular graft & 2048 & 4096 & Pos & Pos & 35 \\
\hline 14 & Male & 59 & Vascular graft & 16384 & 8192 & Pos & Pos & 29 \\
\hline 15 & Male & 74 & Vascular/Spondylodiscitis & 8192 & 8192 & Neg & Pos & 4 \\
\hline
\end{tabular}

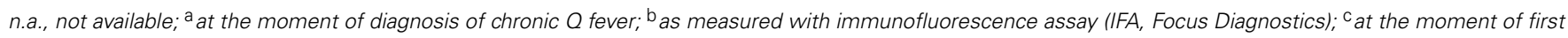
blood sample for this study.

(TEE) showed mild aortic valve insufficiency without vegetations. Although infection of the vascular prosthesis could not be detected with FDG-PET/CT, it was considered the most likely focus of infection. The patient started antimicrobial therapy with doxycycline and hydroxychloroquine after which he made a quick clinical recovery. PCR in serum became permanently negative 5 months after start of therapy. Although anti-phase I IgG titers had decreased from 1:131072 to 1:8192 in 24 months, titers did not decrease further and moxifloxacin was added to the therapy. This regimen was continued for another 14 months, after which it was decided to stop treatment and continue follow-up 3-monthly. The follow-up -6 months so far- was uneventful. This patient, having a good response on the antimicrobial therapy, showed peaking of the IFN- $\gamma / \mathrm{IL}-2$ ratio during the first 9 months. Thereafter, the ratio declined and was stable at lower values during the last phase of the treatment, analog to the anti-phase I antibody titers (Figure 1A).

\section{CASE 2: A PATIENT WITH $C$. burnetii ENDOCARDITIS WITH SUCCESSFUL TREATMENT}

A 66-years-old man had a history of aortic valve stenosis with valvular replacement (homograft) 11 years before. He presented with symptoms of cardiac failure, for which a TEE was performed, which showed vegetations on the valvular prosthesis. Screening for C. burnetii revealed chronic Q fever infection with anti-phase I and II IgG 1:131072 and a positive C. burnetii PCR in blood. Therapy with doxycycline and hydroxychloroquine was started and the patient underwent valvular replacement. PCR on valve tissue was positive for C. burnetii DNA. After 2 months therapy, PCR on blood was negative and remained so in the follow-up. The patient recovered well. Although he suffered from side effects (mainly photo-sensitivity), the antimicrobial therapy could be continued for 27 months, after which 3-monthly follow-up continued. By that time, the anti-phase I IgG had declined to 1:2048. After stop of antimicrobial therapy, the follow-up has been uneventful (13 months so far).

The IFN- $\gamma /$ IL-2 ratio showed an initial increase, but from 5 months after start of treatment onward, the IFN- $\gamma / \mathrm{IL}-2$ ratio declined to very low values (Figure 1B).

\section{CASE 3: A PATIENT WITH $C$. burnetii-INFECTED VASCULAR PROSTHESIS WITH FAILURE OF TREATMENT}

In the aftermath of the $\mathrm{Q}$ fever epidemic, a 64-years-old man presented with an acute aneurysm of the abdominal aorta. In the preceding weeks, he had back pain, fatigue, malaise, and weight loss. He underwent surgery with placement of a vascular prosthesis, and PCR on aorta tissue was positive for $C$. burnetii. Serology revealed elevated titers of anti-phase I and phase II IgG both 1:8192. PCR for C. burnetii DNA in blood was negative. He could not recall a preceding episode of fever or pneumonia. Doxycycline and hydroxychloroquine treatment was started. A transthoracic echocardiogram (TTE) showed thickening of the aortic valve. The patient refused to undergo TEE. He recovered well after the operation. However, anti-C. burnetii IgG titers did not decrease in the subsequent 2 years. PCR for C. burnetii DNA on blood, performed 3-monthly, remained negative. Moxifloxacin was added to the therapy after 23 months. FDG-PET/CT showed increased uptake at the vascular prosthesis, indicating a persistent infection. This patient showed an unsuccessful treatment of a chronic $Q$ fever vascular infection. The IFN- $\gamma /$ IL-2 ratio was relatively low from the start of therapy in this patient. The ratio showed an increase after the operation after which it remained mildly elevated, with no 


\section{A}

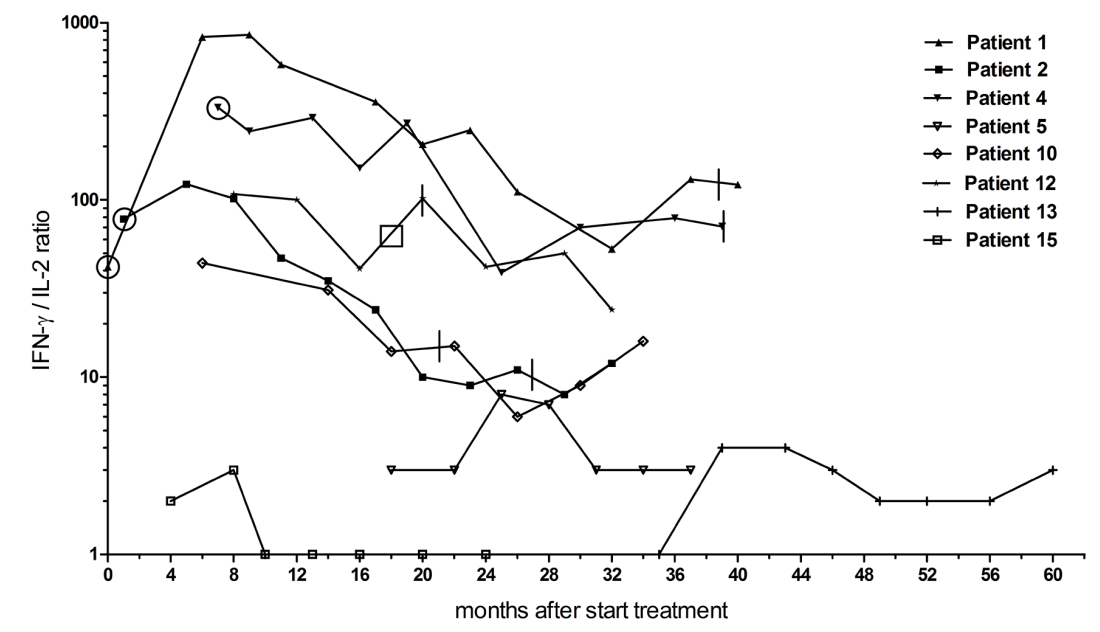

B

UNSUCCESSFUL TREATMENT

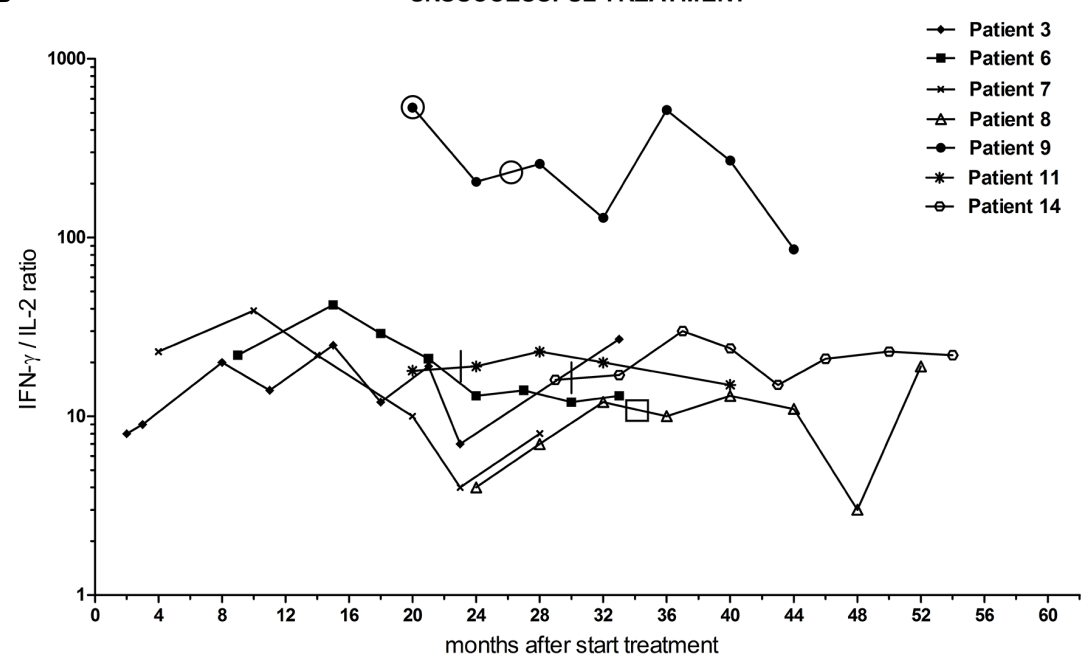

positive PCR for C. burnetii DNA on blood/serum

$\square$ positive PCR for C. burnetii DNA on tissue

| stop of anti-microbial therapy

FIGURE 2 | Interferon- $\gamma /$ IL-2 ratio in $C$. burnetii-stimulated whole blood of chronic $\mathbf{Q}$ fever patients during the study follow-up period, separately shown for (A) patients with successful and (B) patients with

unsuccessful treatment. $t=0$ is start of antibiotic treatment. Treatment was considered successful when 18 months of antibiotic treatment (or 24 months when a prosthesis remained in situ) was completed, and clinically recovery was observed, and a positive PCR for $C$. burnetii DNA on blood became persistently negative, and anti-phase I IgG showed a fourfold decrease or more (related to the maximum titer), and imaging techniques showed disappearance of any (vascular or valvular) infection focus. Circles indicate a positive PCR on blood/serum, squares indicate positive PCR on tissue. Vertical lines indicate stop of antimicrobial treatment. tendency to decline (Figure 1C). This was the result of neither decrease in IFN- $\gamma$ production nor increase in IL-2 production over time.

\section{AN OVERVIEW OF THE IFN- $\gamma /$ /L-2 RATIO IN FOLLOW-UP OF 15 CHRONIC Q FEVER PATIENTS}

We studied the longitudinal IFN- $\gamma /$ IL-2 ratio in fifteen chronic Q fever patients (Table 1). All were followed for at least
18 months during antibiotic treatment. In some cases, this included a period after completion of the treatment. For the purpose of this study, the data of all patients were analyzed according to start of antimicrobial therapy $(t=0)$, which was up to 35 months before inclusion. We divided the group in patients with successful treatment $(n=8)$ and those with unsuccessful treatment ( $n=7$; Figure 2). The latter group did not fulfill the success-criteria because of persistent PCR 




FIGURE 3 | Non-linear regression to straight curves of the longitudinal IFN- $\gamma /$ IL-2 ratios of chronic $\mathbf{Q}$ fever patients. Patients with successful treatment are shown in green, patients with unsuccessful treatment are shown in red. The median ( $(I O R)$ slope of the patients with successful treatment was $-2.10(-7.02$ to -0.06$)$, compared to $-0.15(-1.13$ to 0.25$)$ in patients with unsuccessful treatment $(P=0.19)$.

positivity for C. burnetii in blood (patient 9), less than a fourfold decrease in anti-phase I IgG titer (patient 3, 8, 11, 14), and/or persistent uptake on FDG-PET/CT (patient 3, 6, 7, $8,14)$. As can be seen in Figure 2, the patients with successful treatment had higher maximum IFN- $\gamma / \mathrm{IL}-2$ ratios than those with unsuccessful treatment. Moreover, the IFN- $\gamma / \mathrm{IL}-2$ ratio of the patients with successful treatment showed a more pronounced decrease, each with an individual pattern, compared to the patients with unsuccessful treatment. We performed non-linear regression of the longitudinal IFN- $\gamma / \mathrm{IL}-2$ ratios of each patient to a best-fit straight line (Figure 3). The median $( \pm \mathrm{IQR})$ slope of the patients with successful treatment was $-2.10(-7.02$ to -0.06$)$, compared to $-0.15(-1.13$ to 0.25$)$ in patients with unsuccessful treatment $(P=0.19)$. Because the two main clinical manifestations of chronic $Q$ fever may differ immunologically, the patients with endocarditis were also depicted separately from the patients with vascular (prosthesis) infection (Figure 4). Q fever endocarditis patients had overall higher IFN- $\gamma /$ IL-2 ratios than the vascular $Q$ fever patients.

\section{DISCUSSION}

In the present study, we evaluated the usefulness of longitudinal measurements of cell-mediated immune responses against C. burnetii for treatment monitoring of chronic Q fever. We measured the $C$. burnetii-specific IFN- $\gamma$ and IL-2 production in a wholeblood stimulation assay during a period of at least 18 months follow-up of proven chronic Q fever patients. We observed a trend in which the IFN- $\gamma /$ IL-2 ratio declined when patients experienced a successful outcome of treatment. Patients in whom treatment failed, had overall lower IFN- $\gamma /$ IL-2 ratios, which did not significantly decrease.
The IFN- $\gamma /$ IL-2 ratio reflects the type of effector and memory $\mathrm{CD}^{+}{ }^{+}$T-cell response (Sallusto et al., 1999). Memory T lymphocytes can broadly be defined as two distinct populations of effector memory T-cells and central memory T-cells. IFN- $\gamma$ is predominately produced by effector T-cells and effector memory T-cells, while IL-2 is predominately produced by central memory T-cells. It is postulated that high IFN- $\gamma / \mathrm{IL}-2$ ratio indicates predominance of effector T-cells and effector memory T-cells, resulting from ongoing immunological stimulation by a persistent infection.

The relevance of measuring IFN- $\gamma / \mathrm{IL}-2$ production profiles, as diagnostic correlate of memory $\mathrm{T}$-cell responses, has been studied outside the field of Q fever, specifically in a number of viral infections (Younes et al., 2003; Semmo et al., 2005), and in Mycobacterium tuberculosis infection (Sargentini et al., 2009; Biselli et al., 2010; Casey et al., 2010; Sester et al., 2011; Essone et al., 2014). These studies, as summarized by Lalvani and Millington (2008), show that in acute and chronic infections with a high antigen concentration, e.g., in chronic progressive $\mathrm{HCV}$ infection (Semmo et al., 2005) or untreated tuberculosis (Millington et al., 2007), CD $4^{+}$T-cells predominately secrete IFN- $\gamma$. In infections with persistently low antigen concentrations, e.g., latent asymptomatic cytomegalovirus infection, $\mathrm{CD} 4{ }^{+} \mathrm{T}$-cells secreting IFN- $\gamma$ only, IFN- $\gamma /$ IL-2, or IL-2 only are detected (Harari et al., 2005). In cleared infections, IL-2 secreting $\mathrm{CD}^{+}{ }^{+} \mathrm{T}$-cells predominate (Harari et al., 2004, 2005; Correa et al., 2007; Millington et al., 2007). Our finding that the IFN- $\gamma / \mathrm{IL}-2$ ratio declines during successful treatment of chronic Q fever, assuming a decrease in antigen load, is in accordance with these studies.

The group of patients that was included in our study was inevitably heterogeneous with regard to morbidity, infection status, treatment course and treatment response. Likewise, the inter-individual variation in IFN- $\gamma$ and IL-2 responses was large. We considered it therefore not feasible to combine individual results for a grouped analysis, and chose to describe patients separately. Three patients were described in more detail, because they were followed (almost) from the start of antibiotic treatment. Strikingly, in two of these patients (patients 1 and 2), who seemed to respond well to treatment, the IFN- $\gamma$ production and the IFN- $\gamma /$ IL-2 ratio initially increased, but decreased thereafter. It is tempting to speculate that this initial increase reflects an adequate immune response. A similar initial increase of the specific IFN- $\gamma$ response is seen in patients during treatment for tuberculosis (Sahiratmadja et al., 2007). The patient that still showed signs of infection after more than 2 years of antibiotic treatment (patient 3), had markedly high IL-2 secretion and a low IFN- $\gamma /$ IL-2 ratio from the start, which fluctuated in the follow-up but did not decrease. This might suggest bacterial persistence with low antigen concentrations; an assumption that is supported by the notion that C. burnetii DNA was not detectable in blood, even before start of antimicrobial therapy. The results of the total group of patients with unsuccessful treatment show the same pattern: overall lower IFN- $\gamma /$ IL-2 ratio from the start of follow-up in this study, with no $C$. burnetii DNA detectable in blood. An exception to this rule is patient 9 , who failed on antibiotic treatment by having $C$. burnetii DNA detectable in blood after 20 months of antimicrobial therapy. The lower IFN- $\gamma / \mathrm{IL}-2$ ratio we observed in patients 


\section{A}

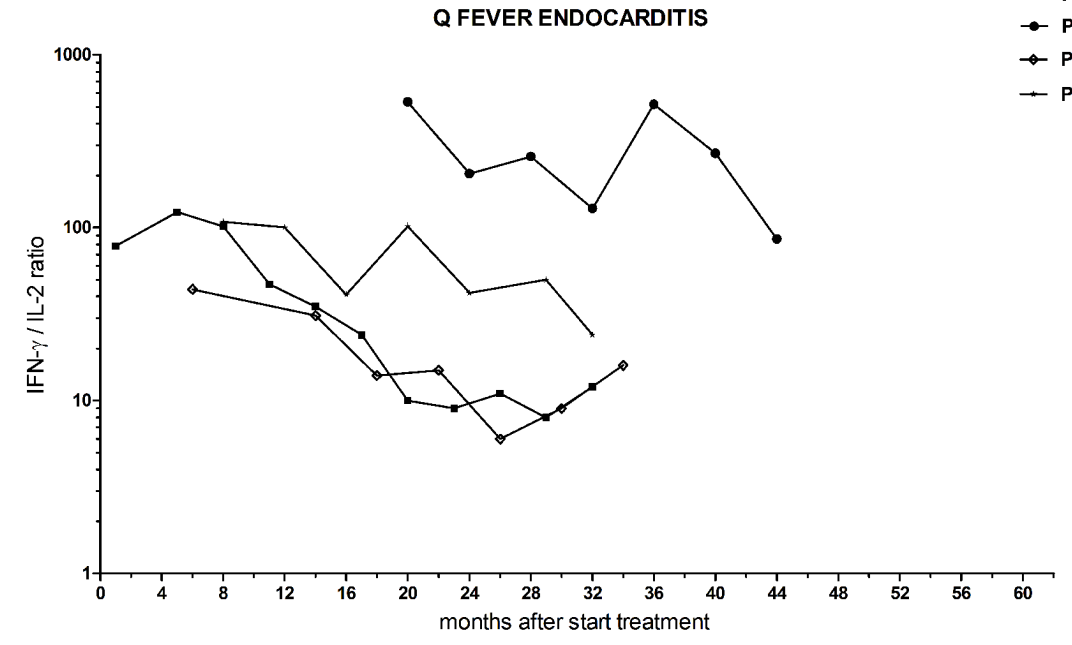

B

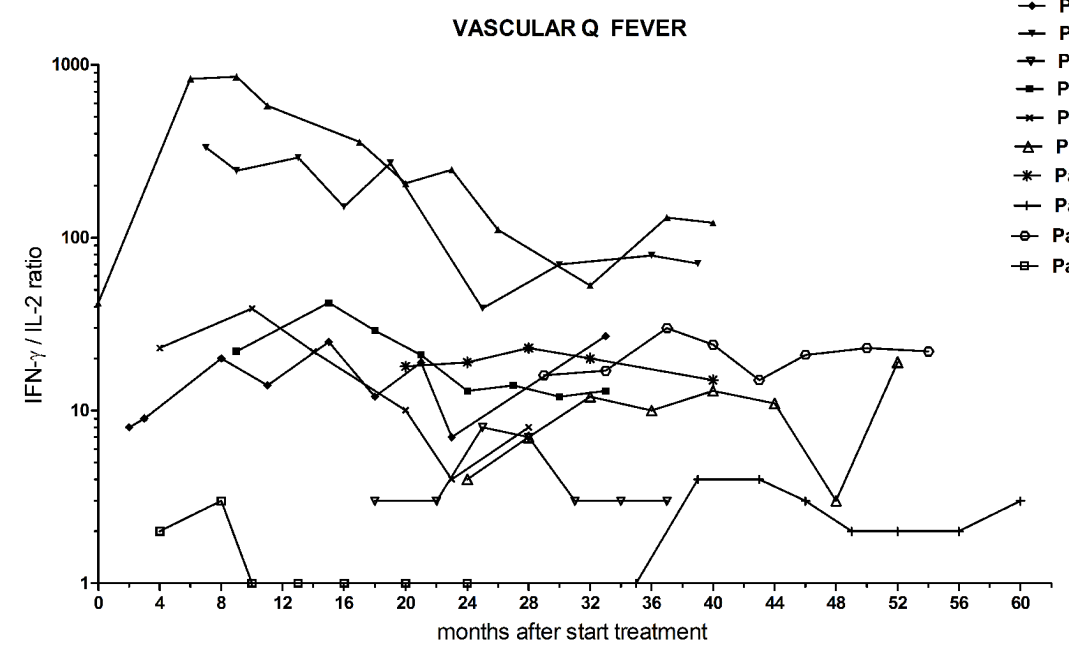

$\rightarrow$ Patient 2

- Patient 9

- Patient 10

- Patient 12

FIGURE 4 | Follow-up IFN- $\gamma$ /IL-2 ratio from chronic $Q$ fever patients during the study follow-up period, separately shown for (A) patients with endocarditis and (B) patients with vascular (prosthesis) infection. $t=0$ is start of antibiotic treatment.

with endovascular infections compared to endocarditis patients suggests that these manifestations of chronic $\mathrm{Q}$ fever differ with respect to antigen concentrations; vascular infections might be a more low-grade infection than endocarditis.

Our study has some limitations. First of all, we studied a relatively small number of patients. Longer follow-up with additional time points after completion of treatment need to be incorporated into future studies to evaluate success of treatment. Moreover, the method we used, in vitro measurement of IFN- $\gamma$ and IL-2 production, does not clearly differentiate whether these cytokines are produced by effector T-cells (producing only IFN- $\gamma$ ) or effector memory T-cells (producing IFN- $\gamma$ and IL-2) or central memory T-cells (producing predominantly IL-2). The ratio IFN$\gamma /$ IL-2 merely reflects the overall result and might be influenced by the total number of circulating T-cells and their viability in vitro. To increase our insight in the matter, detection of cytokine production on single-cell level, e.g., by flow cytometry with intracellular cytokine staining (Harari et al., 2005), would be a valuable addition in future research.

The central position of serology in $\mathrm{Q}$ fever diagnostic is undisputable, and serology has hitherto been the most widely used immunological measurement for C. burnetii infection. It continues to be extensively validated in Q fever research (Frankel et al., 2011; van der Hoek et al., 2011; Edouard et al., 2013; Herremans et al., 2013). Nevertheless, the immunological importance of measuring antibodies in response to this intracellular bacterial infection is questionable. Specifically, the use of antibody titers to monitor the effect of antibiotic treatment on C. burnetii infection and disease needs further research. The definition of serological cure as anti-phase I IgG below 1:800 (or 1:1024 when a commercial IFA is used) is based on expert opinion (Million et al., 2010). The definition of absence of a fourfold decrease in 
antibody titers as a poor prognostic factor, is based on a smallsized retrospective study of Q fever endocarditis (Million et al., 2010), and is not yet confirmed by other studies. In the light of this limited evidence of serology as a biomarker, it would be valuable to also focus on the more relevant cell-mediated immune response. Especially when the decision to continue or stop treatment has to be made in an individual patient, the availability of other relevant biomarkers may be of help. Our study shows a promising role for the IFN- $\gamma / \mathrm{IL}-2$ production profile, although the large variation in IFN- $\gamma /$ IL- 2 ratio between patients in this study makes it difficult to formulate general recommendations for the application of these biomarkers at the current time.

In conclusion, existing clinical, imaging and microbiological parameters to monitor the response to treatment have several limitations. We propose that the IFN- $\gamma / \mathrm{IL}-2$ production profile can be used as an additional immunological biomarker for treatment monitoring of chronic Q fever.

\section{AUTHOR CONTRIBUTIONS}

Conceived and designed the experiments: TS, MGN, JWMvdM, CPBR, MvD. Collected samples: TS, MCWB, MJHP, YEPS, CPBR. Performed the experiments: TS, AA. Analyzed the data: TS, MGN, JWMvdM, CPBR, MvD. TS, JWMvdM, MvD drafted the manuscript and all authors critically revised and approved the final version.

\section{ACKNOWLEDGMENTS}

We gratefully acknowledge the patients that participated in this study. This work was supported by The Netherlands Organization for Health Research and Development [grant number 205520002 to TS].

\section{REFERENCES}

Anderson, A., Bijlmer, H., Fournier, P. E., Graves, S., Hartzell, J., Kersh, G. J., et al. (2013). Diagnosis and management of Q fever-United States, 2013: recommendations from CDC and the Q Fever Working Group. MMWR Recomm. Rep. 62, $1-30$.

Andoh, M., Zhang, G., Russell-Lodrigue, K. E., Shive, H. R., Weeks, B. R., and Samuel, J. E. (2007). T cells are essential for bacterial clearance, and gamma interferon, tumor necrosis factor alpha, and B cells are crucial for disease development in Coxiella burnetii infection in mice. Infect. Immun. 75, 3245-3255. doi: 10.1128/IAI.01767-06

Barten, D. G., Delsing, C. E., Keijmel, S. P., Sprong, T., Timmermans, J., Oyen, W. J., et al. (2013). Localizing chronic Q fever: a challenging query. BMC Infect. Dis. 13:413. doi: 10.1186/1471-2334-13-413

Biselli, R., Mariotti, S., Sargentini, V., Sauzullo, I., Lastilla, M., Mengoni, F, et al. (2010). Detection of interleukin-2 in addition to interferon-gamma discriminates active tuberculosis patients, latently infected individuals, and controls. Clin. Microbiol. Infect. 16, 1282-1284. doi: 10.1111/j.1469-0691.200 9.03104.x

Botelho-Nevers, E., Fournier, P. E., Richet, H., Fenollar, F., Lepidi, H., Foucault, C., et al. (2007). Coxiella burnetii infection of aortic aneurysms or vascular grafts: report of 30 new cases and evaluation of outcome. Eur. J. Clin. Microbiol. Infect. Dis. 26, 635-640. doi: 10.1007/s10096-007-0357-6

Casey, R., Blumenkrantz, D., Millington, K., Montamat-Sicotte, D., Kon, O. M., Wickremasinghe, M., et al. (2010). Enumeration of functional T-cell subsets by fluorescence-immunospot defines signatures of pathogen burden in tuberculosis. PLoS ONE 5:e15619. doi: 10.1371/journal.pone.0015619

Correa, R., Harari, A., Vallelian, F., Resino, S., Munoz-Fernandez, M. A., and Pantaleo, G. (2007). Functional patterns of HIV-1-specific CD4 T-cell responses in children are influenced by the extent of virus suppression and exposure. AIDS 21, 23-30. doi: 10.1097/QAD.0b013e32801120bc
Dellacasagrande, J., Capo, C., Raoult, D., and Mege, J. L. (1999). IFN-gammamediated control of Coxiella burnetii survival in monocytes: the role of cell apoptosis and TNF. J. Immunol. 162, 2259-2265.

Edouard, S., Million, M., Lepidi, H., Rolain, J. M., Fournier, P. E., La Scola, B., et al. (2013). Persistence of DNA in cured patient and positive culture in cases with low antibody levels questioned the diagnosis of Q fever endocarditis. J. Clin. Microbiol. 51, 3012-3017. doi: 10.1128/JCM.00812-13

Essone, P. N., Kalsdorf, B., Chegou, N. N., Loxton, A. G., Kriel, M., Preyer, R., et al. (2014). Bifunctional T-cell-derived cytokines for the diagnosis of tuberculosis and treatment monitoring. Respiration 88, 251-261. doi: 10.1159/0003 65816

Fenollar, F., Fournier, P. E., Carrieri, M. P., Habib, G., Messana, T., and Raoult, D. (2001). Risks factors and prevention of Q fever endocarditis. Clin. Infect. Dis. 33, 312-316. doi: 10.1086/321889

Frankel, D., Richet, H., Renvoisé, A., and Raoult, D. (2011). Q fever in France, 1985-2009. Emerg. Infect. Dis. 17, 350-356. doi: 10.3201/eid1703.1 00882

Harari, A., Petitpierre, S., Vallelian, F., and Pantaleo, G. (2004). Skewed representation of functionally distinct populations of virus-specific CD4 T cells in HIV-1-infected subjects with progressive disease: changes after antiretroviral therapy. Blood 103, 966-972. doi: 10.1182/blood-2003-04-1203

Harari, A., Vallelian, F., Meylan, P. R., and Pantaleo, G. (2005). Functional heterogeneity of memory CD4 $\mathrm{T}$ cell responses in different conditions of antigen exposure and persistence. J. Immunol. 174, 1037-1045. doi: 10.4049/jimmunol.174.2.1037

Herremans, T., Hogema, B. M., Nabuurs, M., Peeters, M., Wegdam-Blans, M., Schneeberger, P., et al. (2013). Comparison of the performance of IFA, CFA, and ELISA assays for the serodiagnosis of acute $\mathrm{Q}$ fever by quality assessment. Diagn. Microbiol. Infect. Dis. 75, 16-21. doi: 10.1016/j.diagmicrobio.201 2.09.001

Kampschreur, L. M., Dekker, S., Hagenaars, J. C., Lestrade, P. J., Renders, N. H., De Jager-Leclercq, M. G., et al. (2012). Identification of risk factors for chronic Q fever, the Netherlands. Emerg. Infect. Dis. 18, 563-570. doi: 10.3201/eid1804.111478

Kersh, G. J. (2013). Antimicrobial therapies for Q fever. Expert Rev. Anti. Infect. Ther. 11, 1207-1214. doi: 10.1586/14787210.2013.840534

Lalvani, A., and Millington, K. A. (2008). T Cells and Tuberculosis: beyond interferon-gamma. J. Infect. Dis. 197, 941-943. doi: 10.1086/529049

Landais, C., Fenollar, F., Thuny, F., and Raoult, D. (2007). From acute Q fever to endocarditis: serological follow-up strategy. Clin. Infect. Dis. 44, 1337-1340. doi: 10.1086/515401

Maurin, M., and Raoult, D. (1999). Q fever. Clin. Microbiol. Rev. 12, 518-553.

Merhej, V., Cammilleri, S., Piquet, P., Casalta, J. P., and Raoult, D. (2012). Relevance of the positron emission tomography in the diagnosis of vascular graft infection with Coxiella burnetii. Comp. Immunol. Microbiol. Infect. Dis. 35, 45-49. doi: 10.1016/j.cimid.2011.09.010

Millington, K. A., Innes, J. A., Hackforth, S., Hinks, T. S., Deeks, J. J., Dosanjh, D. P., et al. (2007). Dynamic relationship between IFN-gamma and IL-2 profile of Mycobacterium tuberculosis-specific T cells and antigen load. J. Immunol. 178, 5217-5226. doi: 10.4049/jimmunol.178.8.5217

Million, M., Thuny, F., Richet, H., and Raoult, D. (2010). Long-term outcome of Q fever endocarditis: a 26-year personal survey. Lancet Infect. Dis. 10, 527-535. doi: 10.1016/S1473-3099(10)70135-3

Pai, M., Riley, L. W., and Colford, J. M. (2004). Interferon-gamma assays in the immunodiagnosis of tuberculosis: a systematic review. Lancet Infect. Dis. 4, 761776. doi: 10.1016/S1473-3099(04)01206-X

Parker, N. R., Barralet, J. H., and Bell, A. M. (2006). Q fever. Lancet 367, 679-688. doi: 10.1016/S0140-6736(06)68266-4

Raoult, D., Houpikian, P., Tissot Dupont, H., Riss, J. M., Arditi-Djiane, J., and Brouqui, P. (1999). Treatment of Q fever endocarditis: comparison of 2 regimens containing doxycycline and ofloxacin or hydroxychloroquine. Arch. Intern. Med. 159, 167-173. doi: 10.1001/archinte.159.2.167

Raoult, D., Marrie, T., and Mege, J. (2005). Natural history and pathophysiology of Q fever. Lancet Infect. Dis. 5, 219-226. doi: 10.1016/S1473-3099(05)7 0052-9

Raoult, D., Tissot-Dupont, H., Foucault, C., Gouvernet, J., Fournier, P. E., Bernit, E., et al. (2000). Q fever 1985-1998. Clinical and epidemiologic features of 1,383 infections. Medicine (Baltimore) 79, 109-123. doi: 10.1097/00005792-20000300000005 
Sahiratmadja, E., Alisjahbana, B., De Boer, T., Adnan, I., Maya, A., Danusantoso, H., et al. (2007). Dynamic changes in pro- and anti-inflammatory cytokine profiles and gamma interferon receptor signaling integrity correlate with tuberculosis disease activity and response to curative treatment. Infect. Immun. 75, 820-829. doi: 10.1128/IAI.00602-06

Sallusto, F., Lenig, D., Förster, R., Lipp, M., and Lanzavecchia, A. (1999). Two subsets of memory T lymphocytes with distinct homing potentials and effector functions. Nature 401, 708-712. doi: 10.1038/44385

Sargentini, V., Mariotti, S., Carrara, S., Gagliardi, M. C., Teloni, R., Goletti, D., et al. (2009). Cytometric detection of antigen-specific IFN-gamma/IL-2 secreting cells in the diagnosis of tuberculosis. BMC Infect. Dis. 9:99. doi: 10.1186/1471-23349-99

Schoffelen, T., Joosten, L. A., Herremans, T., De Haan, A. F., Ammerdorffer, A., Rümke, H. C., et al. (2013). Specific interferon $\gamma$ detection for the diagnosis of previous Q fever. Clin. Infect. Dis. 56, 1742-1751. doi: 10.1093/cid/ cit129

Schoffelen, T., Sprong, T., Bleeker-Rovers, C. P., Wegdam-Blans, M. C., Ammerdorffer, A., Pronk, M. J., et al. (2014). A combination of interferon-gamma and interleukin-2 production by Coxiella burnetii-stimulated circulating cells discriminates between chronic Q fever and past Q fever. Clin. Microbiol. Infect. 20, 642-650. doi: 10.1111/1469-0691.12423

Semmo, N., Day, C. L., Ward, S. M., Lucas, M., Harcourt, G., Loughry, A., et al. (2005). Preferential loss of IL-2-secreting CD4 ${ }^{+}$T helper cells in chronic HCV infection. Hepatology 41, 1019-1028. doi: 10.1002/hep.20669

Seshadri, R., Paulsen, I. T., Eisen, J. A., Read, T. D., Nelson, K. E., Nelson, W. C., et al. (2003). Complete genome sequence of the Q-fever pathogen Coxiella burnetii. Proc. Natl. Acad. Sci. U.S.A. 100, 5455-5460. doi: 10.1073/pnas.0931379100

Sester, U., Fousse, M., Dirks, J., Mack, U., Prasse, A., Singh, M., et al. (2011). Wholeblood flow-cytometric analysis of antigen-specific CD4 T-cell cytokine profiles distinguishes active tuberculosis from non-active states. PLOS ONE 6:e17813. doi: 10.1371/journal.pone.0017813

van der Hoek, W., Versteeg, B., Meekelenkamp, J. C., Renders, N. H., Leenders, A. C., Weers-Pothoff, I., et al. (2011). Follow-up of 686 patients with acute Q fever and detection of chronic infection. Clin. Infect. Dis. 52, 1431-1436. doi: $10.1093 / \mathrm{cid} / \mathrm{cir} 234$
Wegdam-Blans, M. C., Kampschreur, L. M., Delsing, C. E., Bleeker-Rovers, C. P., Sprong, T., Van Kasteren, M. E., et al. (2012a). Chronic Q fever: review of the literature and a proposal of new diagnostic criteria. J. Infect. 64, 247-259. doi: 10.1016/j.jinf.2011.12.014

Wegdam-Blans, M. C., Ter Woorst, J. F., Klompenhouwer, E. G., and Teijink, J. A. (2012b). David procedure during a reoperation for ongoing chronic Q fever infection of an ascending aortic prosthesis. Eur. J. Cardiothorac. Surg. 42, e19-e20. doi: 10.1093/ejcts/ezs217

Younes, S. A., Yassine-Diab, B., Dumont, A. R., Boulassel, M. R., Grossman, Z., Routy, J. P., et al. (2003). HIV-1 viremia prevents the establishment of interleukin 2-producing $\mathrm{HIV}$-specific memory $\mathrm{CD}^{+} \mathrm{T}$ cells endowed with proliferative capacity. J. Exp. Med. 198, 1909-1922. doi: 10.1084/jem.200 31598

Conflict of Interest Statement: A patent application has been submitted by Teske Schoffelen, Mihai G. Netea, Marcel van Deuren, Jos W. M. van der Meer, and others to this Coxiella burnetii specific IFN- $\gamma$ and IL-2 production assay to diagnose Q fever and registered by the number PCT/NL 2013/050167. All other authors declare that they have no conflicts of interest.

Received: 16 December 2014; accepted: 26 January 2015; published online: 12 February 2015.

Citation: Schoffelen T, Wegdam-Blans MC, Ammerdorffer A, Pronk MJH, Soethoudt YEP, Netea MG, van der Meer JWM, Bleeker-Rovers CP and van Deuren M (2015) Specific in vitro interferon-gamma and IL-2 production as biomarkers during treatment of chronic Q fever. Front. Microbiol. 6:93. doi: 10.3389/fmicb.2015.00093

This article was submitted to Infectious Diseases, a section of the journal Frontiers in Microbiology.

Copyright (c) 2015 Schoffelen, Wegdam-Blans, Ammerdorffer, Pronk, Soethoudt, Netea, van der Meer, Bleeker-Rovers and van Deuren. This is an open-access article distributed under the terms of the Creative Commons Attribution License (CC BY). The use, distribution or reproduction in other forums is permitted, provided the original author(s) or licensor are credited and that the original publication in this journal is cited, in accordance with accepted academic practice. No use, distribution or reproduction is permitted which does not comply with these terms. 